\title{
As políticas de formação de pesquisadores: análise comparativa (Portugal-Brasil) em contextos de programas de pós-graduação
}

Naura Syria Carapeto Ferreira *

José Augusto Pacheco **

\section{Resumo}

0 texto analisa, comparativamente, os marcos referenciais das políticas de formação de pesquisadores em contextos de PPGEd em Portugal e no Brasil sobre políticas de formação de pesquisadores. Utiliza o método histórico-crítico para compreender as questões que emergem do uso da comparação apresentando dados e sínteses conceituais que subsidiem novas políticas públicas. Parte do pressuposto da importância do conhecimento científico como instrumento potencial para a compreensão deste empreendimento histórico, pois, se a educação é incapaz de mudar a sociedade desigual hodierna, ela é fonte relevante para compreensão dos fundamentos da desigualdade e para a geração de uma nova institucionalidade no mundo globalizado.Urge demandar um novo ordenamento social em que a regulação seja elemento propulsor de novas políticas intencionais e operacionais que fomentem pesquisas de ponta nestes paises e no mundo globalizado.

Palavras-chave: Pesquisa. Políticas públicas. Formação de pesquisadores.

\section{Researchers training policy: a comparative analysis (Portugal-Brazil) in context of postgraduate programs. Abstract}

This article comes from two researches about researchers and professionals in higher education in the Postgraduate Education training policy in two countries, Portugal and Brazil. From the methodological point of view, we analyze the differences and similarities. We use the comparative historical-critical method to

\footnotetext{
* Professora Titular da Universidade Tuiuti do Paraná; Professora (aposentada) da Universidade Federal do Paraná; Coordenadora do PPG-ED - Mestrado em Educação, UTP, Paraná, BR. E-mail: nauraf@uol.com.br

* Professor Associado c/Agregação, Universidade do Minho (Uminho). Coordenador do Mestrado em Educação, área de especialização em Desenvolvimento Curricular. E-mail: jpacheco@iep.uminho.pt
} 
detect the discrepancies in the two countries and, in particular, within the Program of Postgraduate Stricto Sensu in Education. It seeks to understand some issues that emerge from the comparison and presents a comparative methodological view on the subject of the researchers training policies . In Brazil, the productivity, which is a principle category in business logic, invaded the academic and educational fields as a whole, developing an unprecedented need for production in the history of Brazilian education. In Portugal, and what can be analyzed from the changes in the parameters of the Bologna Process, the research at the postgraduate level has been primarily influenced by the national agency called Science and Technology Foundation. Thence come the conceptual syntheses presented.

Keywords: Researchers training policy. Professionals in education. Comparative methodology

\section{Politica de formación de investigadores: un análisis comparativo (Portugal-Brasil) en el contexto de programas de postgrado. Resumen}

Este artículo proviene de dos investigaciones sobre la política de formación de los investigadores y los profesionales de la educación superior en los programas de postgrado en Educación en dos países, Portugal y Brasil. Desde el punto de vista metodológico, se analizan las diferencias y similitudes.Usamos el método comparativo histórico-crítico para detectar las discrepancias en los dos paises y, en particular, dentro del Programa de Postgrado stricto sensu en Educación. Se trata de entender algunas cuestiones que surgen de la comparación y presenta una visión metodológica comparativa sobre el tema de las políticas de formación de los investigadores. En Brasil, la productividad, que es una categoría de principio en la lógica de negocio, invadió el ámbito académico y educativo en su conjunto, desarrollando la necesidad sin precedentes de la producción en la historia de la educación brasileña. En Portugal, y lo que puede ser analizado en el cambio de los parámetros del proceso de Bolonia, la investigación a nivel de postgrado ha sido influenciada principalmente por el organismo nacional Ilamado Fundación para la Ciencia y la Tecnología. De alli viene la sintesis conceptual presentada.

Palabras clave: Politica de formación de investigadores. Profesionales de la educación. Metodología comparativa

\section{Introdução}

As políticas de formação de pesquisadores coloca, hoje, o desafio em compreender o "Mundo plano" na sua concretude com todas as determinações que apresenta para poder pensá-lo e atuar competentemente. Compromisso em, compreendendo 
o que significa, atender às demandas no sentido da construção de uma nova sociedade verdadeiramente humana onde a fraternidade, a solidariedade e a justiça social sejam reais e não um discurso oco, instrumento de agudização da desigualdade.

0 que vem a ser, então, "Mundo plano? Tem a ver com a "tabula rasa", marco da filosofia empirista de John Locke que valorizava a experiência no processo do conhecer, do saber e do agir, a partir de um estado de "vazio absoluto" que começa a se "constituir" a partir da experiência? Trata-se de uma nova interpretação mais avançada da globalização, definida como uma fase posterior à internacionalização e à multinacionalização porque, ao contrário destas, anuncia o fim dos sistemas nacionais, enquanto núcleo central de atividades e estratégias humanas organizadas? Ou trata-se do que Guiddens (1990, p. 64) já denominou de "a intensificação de relações sociais mundiais que unem localidades distantes de tal modo que os acontecimentos locais são condicionados por eventos que acontecem a muitas milhas de distância e vice-versa, para definir globalização"? Ou, ainda, de um mundo que se tornou "plano", com outro sentido e outro significado dados pela evolução da ciência e da tecnologia, dos meios de comunicação, que permitiram o deslocamento em massa de pessoas, quer como turistas, quer como trabalhadores migrantes ou refugiados, tanto no plano físico como no plano virtual?

Trata-se de uma nova interpretação do mundo além do que se denominou fenômeno da globalização que surge de outra maneira, onde a tecnologia permitiu uma outra forma de comunicação muito mais ampla, incomensurável, onde todos, sem estarem juntos, podem "trabalhar juntos", sem se conhecerem, podem se comunicar numa "interligação" quase sem controle, pois "esse achatamento quer dizer que estamos interligando todos os centros de conhecimento do planeta e costurando uma única rede global" (FRIEDMAN, 2007, p. 19). Trata-se, todavia de uma outra etapa da globalização além das diversas etapas já acontecidas?

Locke (1991)' ao considerar todos os seres humanos intrinsecamente iguais como pressuposto para a aquisição do conhecimento, do processo do saber e do agir, deu base filosófica para combater o status quo vigente, especialmente em relação à aristocracia e à nobreza. A experiência era o ponto de partida para todos e a esta compreensão, que também era um direito, todos poderiam estar sujeitos. De forma embrionária e com outro pressuposto filosófico, já tratava do "direito à educação" para todos.

O significado da "tabula" do século XXI - a "Terra plana" - parte de outro pressuposto: 0 de que o conhecimento está posto no mundo e "graças aos computadores, ao e-mail, às redes, à tecnologia de teleconferência à novos softwares mais dinâmicos" está acessivel a todos. Tudo está à disposição de todos desde que te-

\footnotetext{
${ }^{1}$ Para Locke, todas as pessoas ao nascer o fazem sem saber de absolutamente nada, sem impressões nenhumas, sem conhecimento algum. Então todo o processo do conhecer, do saber e do agir é aprendido pela experiência, pela tentativa e erro?
} 
nham possibilidades de acessar, isto é, que tenham condições de ter, compreender e usufruir a tecnologia de ponta que possibilita este acesso. De outra forma, colocase a "tabula rasa" de Locke em relação à ciência, a tecnologia de ponta e às possibilidade de acessar, de participar. Um outro sentido se põe para a evolução da tencologia existente neste "mundo achatado": o sentido existe para quem pode acessá-la, isto é, não tem sentido para quem não pode acessar que se torna marginalizado desses novos "bens culturais". Em outras palavras, só pode entrar neste mundo quem tem possibilidade de acesso a essa tecnologia!

Ensaiando esta nova forma de pensar o "mundo plano", pretende-se analisar a importância e os marcos referenciais das políticas de formação de pesquisadores em contextos de Programas de Pós-graduação em Educação em Universidades de Portugal e do Brasil, expondo resultados de investigações realizadas e em curso que visam a subsidiar as políticas públicas e a contribuir para a melhoria da qualidade desta formação num mundo considerado como o acima exposto e que passa a ser o referencial para a formação de pesquisadores. Utiliza-se o método histórico-crítico que permite detectar as contradições existentes nos dois paises e, em especial, no interior dos Programas de Pós-graduação em Educação no que concerne à formação de pesquisadores.

\section{Políticas de formação de pesquisadores: um novo significado e um novo sentido}

Pensar a formação de pesquisadores requer situar, esta formação, no contexto que the dá sentido e significado, de onde vêm estes seres em formação e para onde se destinam.

0 processo de globalização, eminentemente econômico e tecnológico, da sociedade opulenta exclusiva e discricionária, organizou um "mercado de fato global, com a venda e revenda de produtos de mão de obra em escala mundial, dando ensejo à chamada "Sociedade Transbordante" que abunda de sentidos e significados multifacetados, onde o matar e o morrer, a mentira, a trapaça, a traição, a ignomínia, assim como todas as formas de violência humana veiculadas através da mídia, de forma naturalizada são, já, conceitos incorporados, por todas as pessoas que têm acesso à mídia e aos meios de comunicação formais e informais.

A constatação de que o "mundo é plano" na demominação dada por Thomas Friedman (2007), que efetivamente "está se achatando", "aplainando", incorpora todas estas análises. Significa dizer que se está interligando todos os centros de conhecimento do planeta e costurando uma única rede global, "o que (se a política e o terrorismo não atrapalharem) pode possibilitar uma era notável de prosperidade, inovação e colaboração entre empresas, comunidades e individuos" (FRIEDMAN, 2007). E o próprio autor, logo a seguir, afirma:

[...] a idéia de uma terra plana também me deu medo, tanto em termos profissionais, quanto pessoais. A razão pessoal era consequência do fasto óbvio de que, num mundo pla- 
no, não só os programadores e aficionados pelos computadores que são brindados coma possibilidade de trabaIharem juntos, mas também a Al-Queda e outras redes terroristas. Não estamos aplainando o terreno somente no sentido de agregar e expandir oportunidades de um novo grupo de inovadores; estamos possibilitando também a agregação e a capacitação de um outro grupo novo, esse de indivíduos frustrados, oprimidos e cheios de ódio( FRIEDMAN, 2007, p. 19).

Pensando por contradição, o oposto também é possivel, como um "achatamento" do mundo que vai possibilitar o terrorismo, o ódio e o domínio servil. Um mundo que pode subjugar, ainda mais o sul ao norte, os países de periferia aos países centrais do planeta. Significa emergir um novo paradigma sequencialmente à formulação histórica acima referida, que está a incitar educadores e gestores a pensar na importância, sentido, responsabilidade e compromisso da pesquisa e da formação de pesquisadores comprometidos com uma sociedade mais fraterna e justa.

\section{A pesquisa e a formação de pesquisadores}

Sabe-se que a objetividade do conteúdo do nosso pensamento, a coincidência das leis do pensamento com as leis do ser é obtida e verificada pela ação prática do homem sobre a natureza, sobre o seu entorno.

Portanto "o reflexo da natureza na consciência do homem não é algum estado ancilosado, inerte ou mecânico, não é uma cópia morta da realidade, mas um processo dinâmico de aprofundamento na essência das coisas para poder se apropriar, compreendendo-a para acrescentar ao já existente produzido pelo conjunto da humanidade, a contribuição que nos cabe como integrantes do mundo humano, neste estágio histórico de nossas existências (FERREIRA, 2007b).

Este é o fundamento ontológico da pesquisa e, em especial da pesquisa na pósgraduação stricto sensu, lócus de formação do pesquisador e a importância da ciência e da investigação no processo do conhecimento.

No Brasil, a produtividade, que é uma categoria de princípio na lógica empresarial, invadiu o domínio acadêmico e educacional como um todo, desenvolvendo uma necessidade de produção jamais vista na história da educação brasileira. 0 processo de orientação de dissertações e teses, no Brasil, vem sendo marcado, pela "angústia" dos prazos, critérios quantitativos estabelecidos pela Coordenação de Aperfeiçoamento de Pessoal de Nivel Superior (Capes) que exige qualidade de excelência num mínimo de tempo de 24 meses entre o processo seletivo e a defesa. Os alunos, oriundos de todas as áreas, não possuem as leituras necessárias à compreensão do seu próprio 
objeto de investigação, quando este já existe, mesmo sabendo por, reiteradamente, apregoar-se que uma dissertação e uma tese têm que ser originais, importantes, viáveis e possuir uma destinação social com questões propositivas ou com um encaminhamento do que Saviani (1991) denomina "monografias de base"2.

Os orientadores (denominados tutores em Portugal) veem na "luta" de orientar mestrandos e doutorandos num prazo escasso de tempo para fundamentação e aprendizado da pesquisa. Todavia, faz-se de tudo para superar a exiguidade de tempo para o acúmulo de compromissos, envolvendo, cada vez mais os orientando, através dos grupos de pesquisa, no trabalho acadêmico, organizando em conjunto atividades complementares, debates e organização de eventos para um real aprendizado do espírito acadêmico.

A academia brasileira vive, além da pressão da Capes pela "produtividade" quantitativa por parte dos pesquisadores e orientados - objeto de sustentação e de avaliação de um Programa de Pós-graduação -, a necessidade de participar do ensino na graduação, da extensão, de trabalhos relevantes na comunidade que se possam caracterizar como impacto social. Isto vai exigir muito mais do pesquisador que tem que orientar seus orientandos nas pesquisas em desenvolvimento nos "grupos de pesquisa" constituídos pelas pesquisas dos orientadores aos quais estes têm que pertencer e, ainda, a "cobrança" da participação no ensino e na extensão atendendo critérios de "impacto e inserção social" em nível nacional e internacional, e da participação em eventos nos dois âmbitos com inscrição de trabalho.

0 rigor da Capes sobre os Programas de Pós-Graduação, postos à parte os prazos e os financiamentos contraditoriamente, todavia, revela um teor de orientação de qualidade, pois fornece os quesitos que serão avaliados e exige o seu cumprimento fornecendo, dessa forma, uma orientação a ser seguida porque vai ser avaliada. Os indicadores da ficha de avaliação amplamente divulgados pela Capes são hoje um modelo no mundo, pelo rigor e cuidado com a formação do pesquisador e a produção do conhecimento. Apenas os prazos e o financiamento é que não correspondem ao nível de exigência, gerando ônus para professores e alunos que necessitam trabalhar, estudar, organizar e participar de eventos, com produção intelectual e técnica de impacto social com significativa inserção social - quesitos que fazem os Programas se comprometerem com as questões candentes da educação que a pós-graduação necessita trabalhar e, até, resolver, fornecendo proposições e formas alternativas de soluções através de suas pesquisas.

A orientação coletiva no Brasil tem-se revelado muito rica, como processo, quando pode acontecer, embora prejudicada pelos mesmos óbices acima apontados. 0 processo de orientação coletiva proporciona discussões e engendra incriveis diferenças entre os participantes de um grupo de pesquisa. A ótica com que cada um "vê" o

\footnotetext{
${ }^{2}$ Saviani (SAVIANI, 1991, p. 44) afirma que "se é verdade que consistentes estudos de base são condição para alcançar vôos interpretativos arrojados, também é verdade que, sem a indicação de direções, isto é, sem um referencial teórico que mobilize hipóteses, dificilmente surgirão 'monografias de base'".
} 
objeto em questão revela sua compreensão e muitas outras facetas ainda não observadas. Ai se revela o sentido político da construção epistemológica, visto que as finalidades e o contexto que referencia a análise abre um "mundo" de possibilidades.

Tal participação possibilita o desenvolvimento do espírito crítico e da aceitação da crítica, formas solidárias e fraternas de "ajuda" e "quebra" de existência de uma possivel autossuficiência. Infelizmente o tempo para o desenvolvimento desta rica forma de trabaIho é quase inexistente, diante das inúmeras demandas que o orientador "sofre" no seu percurso de trabalho, mas, mesmo assim, "fabrica tempo" para poder fazê-la acontecer.

Em Portugal, e no que pode ser analisado sobre a mudança nos parâmetros do Processo de Bolonha, a pesquisa em nível da pós-graduação tem sido basicamente influenciada pela Agência nacional denominada Fundação para a Ciência e Tecnologia. 0 financiamento existente depende de dois níveis de intervenção - concurso de projetos e financiamento de Centros de Investigação - avaliados por equipes internacionais. Esta avaliação internacional, nem sempre coerente com um modelo validado a nível institucional, está não só a guiar-se por critérios normativistas, impostos pelo governo, entre os quais se citam frequentemente a publicação em língua inglesa e a opção por metodologias de natureza quantitativa, bem como a impor temáticas prioritárias, ligadas a problemas sociais.

Para o caso de Portugal, e explorando a noção de tutoria em trabalhos de pesquisa ao nível da pós-graduação, tanto em cursos lato senso como em cursos stricto senso, observa-se uma situação diferente da que existe no Brasil, pois não existe nem o controle de agências de financiamento nem um controle institucional significativo, decorrente de organismos nacionais, em termos administrativos.

De acordo com o regulamento jurídico do ensino superior, a pós-graduação é da responsabilidade das instituições de ensino superior, de acordo com os normativos que estipulam os ciclos de formação, no âmbito do Processo de Bolonha (DecretoLei $n^{\circ} .74 / 2006$, de 24 de Março), e que estabelecem princípios gerais quer para a avaliação (Decreto-lei no. 38/2007, de 16 de Agosto), quer para a acreditação (Decreto-lei $n^{\circ}$. 369/2007, de 5 de Novembro).

Com efeito, tal controle sobre a pós-graduação é mais administrativo do que curricular, outorgando-se à burocracia do ministério a adequação dos cursos aos itens previamente formulados e a organismos internacionais a sua avaliação no contexto da avaliação institucional externa.

Se há um organismo nacional, a Direção Geral do Ensino Superior, que estipula regras para a acreditação dos cursos de pós-graduação, num processo meramente administrativo, não existe, por sua vez, uma agência que tenha a função de avaliar 
os cursos de os fechar ou manter em função dos resultados. Tal avaliação faz parte, como se referiu, de um processo mais amplo de avaliação da qualidade do ensino e do cumprimento dos objetivos a que cada instituição se propõe.

De acordo com as normas de organização dos processos referentes ao registro dos ciclos de estudos, o processo deve ser elaborado na base dos seguintes critérios: o ensino deve ser baseado no desenvolvimento de competências; a formação deve ser ministrada para os objetivos específicos; a determinação do trabalho que o estudante deverá desenvolver em cada unidade curricular e a fixação do número total de créditos, e consequente duração do ciclo de estudos.

Perante tal autonomia, cada universidade, privada ou pública, pode ministrar cursos, desde que cumpra determinadas cláusulas, e perante a ausência de mecanismos de regulação a nível estatal. 0 que impera é a lógica de mercado.

Quer dizer, pois, que a frequência de um curso, de especialização, mestrado ou doutoramento, depende do mérito do aluno e, sobretudo da sua capacidade para 0 pagamento das taxas, na medida em que não beneficia de qualquer apoio financeiro nem da dispensa de serviço docente, no caso de ser professor ou professora. Por conseguinte, inexistem na pós-graduação portuguesa mecanismos diretos de controle, estabelecidos à escala nacional, na supervisão das dissertações de mestrado ou teses de doutoramento, ainda que as instituições possam ter normas próprias, mas sempre muito generalistas. A ausência de um controle institucional sobre processos de supervisão, como os que são ditados por prazos rigorosos, faz com que sobressaia, neste processo, o percurso individualizado do mestrando/doutorando.

Porém, e porque não existe um controle administrativo marcante, pois o sucesso, em termos formais, do curso não depende do número daqueles que terminam os seus trabalhos, a relação tutorial é essencialmente determinada pelo ritmo de trabalho do orientando. Ao não existir a obrigatoriedade administrativa de realizar os encontros de supervisão, admitindo-se que a lógica individual prevalece sobre a lógica de grupo, com exceção das primeiras sessões, a relação tutorial depende de uma motivação intrínseca ao próprio orientando, o que, decerto, explica a elevada percentagem de mestrandos que conclui a parte curricular do curso e que depois não elabora a dissertação.

Mesmo assim, e porque a tecnologia não pode substituir a relação pedagógica de uma tutoria, é fundamental que orientador e orientando tenham entre si momentos de conversa formais e/ou informais, com o sentido não só de esclarecer aspectos fundamentais de um trabalho de pesquisa, bem como de trocar informação diversa. A relação tutorial num contexto de supervisão de trabalhos acadêmicos depende, pelo menos no contexto da minha experiência, de dois fatores principais: motivação do orientando, sendo admissivel que registre momentos de euforia e de distanciamento, 
tal como um novel condutor se sente nos primeiros meses no manejo de um carro; persistência do orientador, fazendo-lhe crer que é capaz de elaborar o trabalho e que todos os dias são dias de pesquisa, por mais distanciado que esteja dos trabalhos.

A desistência de muitos pesquisadores pode ser atribuida à falta de um trabalho persistente, acreditando que hoje não é possivel e que, mais para a frente, haverá tempo para a realização das tarefas.

Um mecanismo que pode fortalecer a relação tutorial com vista à realização do estudo de pesquisa é o estabelecimento de metas conjuntas, em função do cumprimento de prazos concretos, incluindo a publicação de textos. Mais do que impor o cumprimento rigoroso do cronograma que faz parte do projeto de pesquisa, é necessário que orientador e orientando se comprometam mutuamente no que diz respeito à obtenção de resultados concretos, por exemplo, realização do estado da arte no âmbito da identificação e contextualização do problema de pesquisa, elaboração da instrumentação, recolha e análise de dados.

A realização destas tarefas pode, de igual modo, potenciar a produção conjunta de textos, que podem ser apresentados, de preferência, em congressos, seminários e colóquios, e enviados para revistas científicas. Tal prática pode servir de motivação ao orientando, facilitando a sua integração progressiva em meios acadêmicos, onde encontra outros interlocutores. A pertença do mestrando ou doutorando em projetos de investigação, liderados ou não pelo seu orientador, torna possivel ultrapassar muitos obstáculos, já que o seu trabalho se torna uma das facetas de uma pesquisa mais ampla, podendo beneficiar de outros contributos conceptuais e metodológicos.

Deste modo, em contextos de pós-graduação e em termos de supervisão de trabalhos de pesquisa, a relação tutorial é fundamental para o êxito pessoal e acadêmico do orientando. Para além de uma função meramente supervisiva, o tutor necessita de saber ler o percurso do seu orientando, ajudando-o a realizar as tarefas com vista à produção de uma investigação.

\section{A guisa de conclusão}

0 denominado "mundo plano" possui uma plataforma que é "produto da convergência entre computador pessoal (que permitiu a cada individuo tornar-se autor de seu próprio conteúdo em forma digital), o cabo de fibra ótica (que subitamente permitiu a todos aqueles indivíduos acessar cada vez mais conteúdo digital no mundo por quase nada) e o aumento dos softwares de fluxo de trabalho (que permitiu aos individuos de todo o mundo colaborar com aquele mesmo conteúdo digital estando em qualquer lugar, independente da distância entre eles). Ninguém previu esta convergência. Ela simplesmente aconteceu, bem em torno do ano 2000. E quando aconteceu, as pessoas do mundo inteiro começaram a acordar e perceber que tinham mais poder do que nunca para se tornarem globais como indivíduos, 
que precisavam mis do que nunca pensar em si próprias como indivíduos competindo com outros indivíduos em todo o planeta, e que tinham mais oportunidade para trabalhar com esses outros individuos e não só competir com eles" Como resultado, " cada pessoa agora precisa, e pode, perguntar: como é que eu me insiro na concorrência global e nas oportunidades que surgem a cada dia e como é que eu posso, por minha própria conta colaborar com outras pessoas em âmbito global? (FRIEDMAN, 2007, p. 21-22)

Tal reflexão nos faz pensar em formular outras perguntas: Como podem os Programas de formação de pesquisadores no mundo comprometer-se com esse mundo que pertence só aos que podem ter acesso a esses bens que a ciência e a tecnologia disponibilizou? Quem pode, no conjunto da população mundial, em especial nos paises de periferia, possuir computador pessoal, o cabo de fibra ótica e os softwares de ponta de fluxo de trabalho que permitem "ver" e participar efetivamente deste mundo plano? Colocam-se estas questões para reflexão, visto que no limites deste texto não podem ser exploradas.

Tanto em Portugal como no Brasil, os resultados dos estudos realizados evidenciam que urge demandar um novo ordenamento social. A educação é uma instituição necessária para incorporar a população a todo tipo de transformação social, efetiva, que se pretenda. Dai a importância do conhecimento científico como instrumento potencial para a compreensão deste empreendimento histórico, pois como é sobejamente conhecido, se a educação é incapaz de mudar a sociedade desigual em que se vive, ela é fonte relevante e significativa passaporte - para compreensão dos fundamentos da desigualdade e para a geração de uma nova institucionalidade no mundo globalizado, neste novo "mundo plano".

\section{Referências}

FERREIRA, N. S. C. A gestão do conhecimento: da produtividade à produção da humanização da formação. In: (Org.). A pesquisa na pós-graduação em educação: reflexões, avanços e desafios. Curitiba, 2007b. (Cadernos de Pesquisa; n. 3).

FRIEDMAN, T. L. O mundo é plano: uma breve história do século XX. Rio de Janeiro: Objetiva, 2007.

GUIDDENS, A. Sociology. Oxford: Polity Press, 1990.

LOCKE, J. Ensaio sobre o entendimento humano. 5. ed. São Paulo: Nova cultural, 1991. (Os Pensadores).

SAVIANI, D. Tendências e correntes da educação brasileira. In: MENDES, D. T. Filosofia da educação brasileira. Rio de Janeiro: Civilização Brasileira, 1991.

Recebido em: 14/10/2009

Aceito para publicação em: 05/11/2009 